\section{Apolipoprotein C-I}

K. J. Lackner ${ }^{1}$ und D. Peetz ${ }^{2}$

${ }^{1}$ Institut für Klinische Chemie und Laboratoriumsmedizin, Universitätsmedizin Mainz, Mainz, Deutschland

${ }^{2}$ Institut für Labormedizin, Helios Klinikum Berlin-Buch, Berlin, Deutschland

\section{$\operatorname{Synonym(e)~ApoC-I~}$}

Englischer Begriff apolipoprotein C-I
Definition ApoC-I ist ein Apolipoprotein der triglyzeridreichen $>$ Lipoproteine und High Density Lipoproteine (HDL; s. $>$ High Density Lipoprotein).

Funktion - Pathophysiologie ApoC-I ist ein ca. 6,7 kDa großes Protein, das als 83 Aminosäuren langes Proprotein in der Leber und gering auch im Dünndarm synthetisiert wird. Im Plasma überwiegend an $>$ Very low density Lipoprotein und HDL gebunden. Wie ApoC-III moduliert ApoC-I die Interaktion von Remnant-Partikeln mit hepatischen Rezeptoren. Es hemmt die $>$ Phospholipase A2 und evtl. auch $>$ Lecithin-Cholesterin-Acyltransferase im Plasma. 